\title{
Temperature-maternal age interactions on wing traits in outbred Drosophila mercatorum
}

\author{
Anders Kjærsgaard ${ }^{1, *}$, Søren Faurby ${ }^{1}$, Kristian $\operatorname{Krag}^{1}{ }^{1}$, Volker Loeschcke $^{1}$, \\ Cino Pertoldi ${ }^{1,2}$ \\ ${ }^{1}$ Ecology and Genetics, Department of Biological Sciences, Ny Munkegade, Building 1540, Aarhus University, \\ DK-8000 Aarhus C, Denmark \\ ${ }^{2}$ Mammal Research Institute, Polish Academy of Sciences, Waszkiewicza 1c, 17-230 Białowieża, Poland
}

\begin{abstract}
Drosophilid wings have often been used to investigate maternal effects of age and phenotypic plasticity in response to developmental temperature. However, temperature-maternal age interactions have been given little attention despite their potentially important role in driving evolution. Climatic change and anthropogenic intervention can possibly influence the age structure of a population, leading to a larger proportion of individuals reproducing at old age due to low recruitment. Here we investigated the morphometric traits wing length and wing width as well as the composite trait wing aspect (wing width/wing length) of the offspring of young ( 3 to $6 \mathrm{~d}$ ) and old (15 to $18 \mathrm{~d})$ mothers at 3 rearing temperatures $\left(20,25\right.$ and $\left.28^{\circ} \mathrm{C}\right)$. We used 2 different strains of highly heterozygous, yet genetically identical, individuals. We found significant effects of maternal age and rearing temperature on wing size and wing shape characterised by PC1 and PC2, respectively; however, the interaction was highly significant only in Strain 2, but close to significant in Strain 1 . The analysis of phenotypic plasticity of wing length in response to temperature did not reveal any difference between offspring of young and old mothers. For wing width, the response was significantly different from 20 to $25^{\circ} \mathrm{C}$ in Strain 1 but not in Strain 2. The composite trait, wing aspect, was highly significant from 20 to $25^{\circ} \mathrm{C}$ in Strain 1 and significant in Strain 2 from 25 to $28^{\circ} \mathrm{C}$. The main implication of the observed results is that climatic factors, such as temperature, may interact with maternal effects of age to potentially exacerbate phenotypic plasticity.
\end{abstract}

KEY WORDS: Aging $\cdot$ Morphometrics $\cdot$ Wing size $\cdot$ Wing shape

Resale or republication not permitted without written consent of the publisher

\section{INTRODUCTION}

Phenotypic plasticity, the capacity of a genotype to produce different phenotypes in response to different environments, such as different temperature regimes, has been fairly well studied for morphometric traits of drosophilid wings. The same is the case for maternal effects of age. Maternal effects, or parental effects more generally, are the non-genetic effects transferred across generations (Rossiter 1996). However, few studies so far have attempted to analyse the interaction between the extrinsic factor of temperature on developmental plasticity of offspring in response to the intrinsic factor of maternal age at reproduction (Hercus \& Hoffmann 2000, Faurby et al. 2005), even though natural populations often experience this combination.
If a population is not capable of tracking environmental changes adequately, it is likely to show decreased average fitness, leading to a shift in the age structure of the population. The result will be a larger proportion of old individuals due to low recruitment (Templeton \& Johnston 1982). It has recently been highlighted that it is important to incorporate several factors in analyses of temperature changes (Chown et al. 2010, this Special) and the incorporation of maternal age in such analyses may therefore be highly relevant.

There are several types of parental effects and it appears that they can be strongly shaped by selection (Mousseau \& Fox 1998, McIntyre \& Gooding 2000, Badyaev \& Uller 2009). In line with this, there is some evidence that maternal age can be of selective importance. The presence of old flies may indicate a stable, 
competition-driven environment which could make investment in fewer but larger offspring advantageous (Templeton \& Johnston 1982, Faurby et al. 2005, Røgilds et al. 2005). Another important aspect of parental age is senescence, since very old mothers may suffer from build-up of oxidative stress which may reduce the amount of energy they can allocate to reproduction (Halliwell \& Gutteridge 1999).

The combined effect of parental age and temperature may be of importance in meta-population dynamics, particularly if accompanied by inbreeding in the subpopulations. The age structure of sink populations is likely to be dominated by older age classes relative to source populations (Pulliam \& Danielson 1991, Nieminen et al. 2004). A comprehensive understanding of rescue effects therefore needs to incorporate age structure as well as other types of parental effects. Since more and more populations are expected to conform to meta-population structure because of the continued fragmentation of habitats (Young \& Clarke 2000), the effects of age structure and genetic structure may become increasingly important, especially in light of the increase in average temperatures and the frequency of extreme weather events caused by global warming forcing populations to respond to the imposed stress. There are several ways in which this can be mediated: a population can shift its range to avoid the stressor, adapt through selection or it can react by a plastic response.

Drosophila wings are well suited for investigating the combined effects of maternal age and temperature as changes in wing parameters have been documented repeatedly for both of these factors (Hercus \& Hoffmann 2000, Faurby et al. 2005). Wing size and shape in Drosophila have been found to be highly plastic in their response to temperature (David et al. 1997, Loeschcke et al. 1999). Wing size shows a consistent trend both in studies of natural populations of Drosophila and in the laboratory, with smaller wings being produced in smaller flies in warmer environments (Imasheva et al. 1998, Loeschcke et al. 2000, Hoffmann \& Shirriffs 2002) in accordance with the temperaturesize rule (Atkinson \& Sibly 1997, Angilletta et al. 2004).

Patterns in wing shape changes with temperature are less clear than those in wing size. Wing shape has been suggested to be regulated to a higher degree by genetic factors than wing size (e.g. Workman et al. 2002, Breuker et al. 2006), but studies using parthenogenetic flies have shown that responses to temperature are partially plastic (Andersen et al. 2005, Faurby et al. 2005, Kjærsgaard et al. 2007). Although trends in wing shape changes with temperature are still somewhat elusive, some observations and ecological theories of an adaptive role have been put forth. Wing aspect, a ratio of wing width to wing area or wing length, has often been used as a measure of wing shape variation which is not simply ascribed to changes in allometric wing size (Azevedo et al. 1998, Hoffmann \& Shirriffs 2002, Carreira et al. 2006, Santos et al. 2006). Shape changes independent of size variation have been found in several studies in different Drosophila species and by means of different analytical approaches (Weber 1992, Bitner-Mathé \& Klaczko 1999, Hoffmann \& Shirriffs 2002, Kjærsgaard et al. 2007), and there is some evidence that wing shape is related to fitness (Cavicchi et al. 1991, Kölliker-Ott et al. 2003, Carreira et al. 2006). A decrease in wing aspect with temperature has usually been found in line with the theoretical expectations (Hoffmann \& Shirriffs 2002, Santos et al. 2006, Loh et al. 2008, but see Gilchrist et al. 2000) but apparently parallel selection is not operating among different Drosophila species (Loeschcke et al. 1999, 2000, Gilchrist et al. 2000, Hoffmann \& Shirriffs 2002). The reduction in wing size with temperature often does not merely reflect linear scaling with overall structural size. Stalker (1980), for instance, observed a decrease in wing loading (wing size:body size ratio) with temperature in $D$. melanogaster, so that flies reared at high temperatures generally had smaller wings relative to body size. This finding was hypothesized to be due to lower wing beat frequency at lower temperature (Reed et al. 1942), which is then compensated for by larger wings capable of producing larger lift. This relationship has also been found in other studies (Starmer \& Wolf 1989, Petavy et al. 1997, Azevedo et al. 1998, Loeschcke et al. 1999, Hoffmann et al. 2007, but see e.g. Gilchrist \& Huey 2004).

In the present study we analysed how maternal age influences temperature-induced plasticity of wing size and shape. We analysed data from an outbreeding event at old age as compared to that at young age using parthenogenetic mothers and inbred sexual fathers in order to generate a close to genetically identical heterozygous population. The use of parthenogenetic mothers is highly advantageous as it enabled us to use a well-known study organism and at the same time greatly reduce the potential confounding effect of genetic variation. Obviously, genetic variation acts to increase the variance of a given trait unless it is strongly canalised, thus reducing statistical power. On the other hand, inbreeding can result in increased developmental instability (Lerner 1954, Pertoldi et al. 2006), which can be measured as an increase in the variance of the trait measured. These issues are largely circumvented with the approach used in the present study, which ensures that individuals are genetically nearly identical while at the same time harbouring high heterozygosity. Previous studies have found that older mothers produce larger offspring (e.g. McIntyre \& Gooding 2000, Faurby et al. 2005) and that higher 
rearing temperatures result in smaller offspring (e.g. David et al. 1994, Bochdanovits \& de Jong 2003). It cannot, however, be predicted a priori whether the temperature plasticity of wing size and shape and the composite trait, wing aspect, measured here as log(wing length/wing width), of old mothers should differ from that of younger mothers in an outbred population.

\section{METHODS}

\subsection{Experimental design}

We used 2 facultative parthenogenetic lines of Drosophila mercatorum, referred to as Strains 1 and 2, and a sexually reproducing, highly inbred strain (see Krag et al. 2009 for further details). The flies were maintained on instant Drosophila medium (Carolina Biological Supply) and a $12 \mathrm{~h}$ light:12 h dark cycle. The parthenogenetic females were crossed with the inbred males to form an outbreeding event. This was done at 2 different ages. Females at 3 to $6 \mathrm{~d}$ of age (postemergent age) and again at 15 to $18 \mathrm{~d}$ of age were mated with males of 3 to $6 \mathrm{~d}$ of age. During the experiment, all parent flies were kept and mated at $25^{\circ} \mathrm{C}$. After mating, the vials with eggs were randomly assigned to 20,25 and $28^{\circ} \mathrm{C}$, respectively, and left to develop the $F_{1}$ generation, giving a total of 12 treatments: 2 lines, 2 age classes and 3 temperatures. The offspring from the young mothers were previously analysed in a study on the effect of outbreeding on young females (Krag et al. 2009). Since the present study compared all female parthenogenetic offspring with the outcome of the same lines reproducing sexually, we only used females in the present experiment.

\subsection{Measurements}

Wings were removed from the flies and placed in a droplet of lactic acid on a microscope slide and covered with a cover slip. Digital images were obtained using a camera connected to a dissecting microscope with the software IM1000 version 1.2. We measured 9 landmarks on the left wing (Fig. 1) using the software ImageJ (version 1.33u; Abramoff et al. 2004) and calculated the 36 connecting distances (see Faurby et al. 2005 for further details including measurement errors).

\subsection{Statistical analysis}

Principal component analyses (PCAs) were performed on each strain and further analyses were performed on the loadings of PC1 and PC2. A 2-way

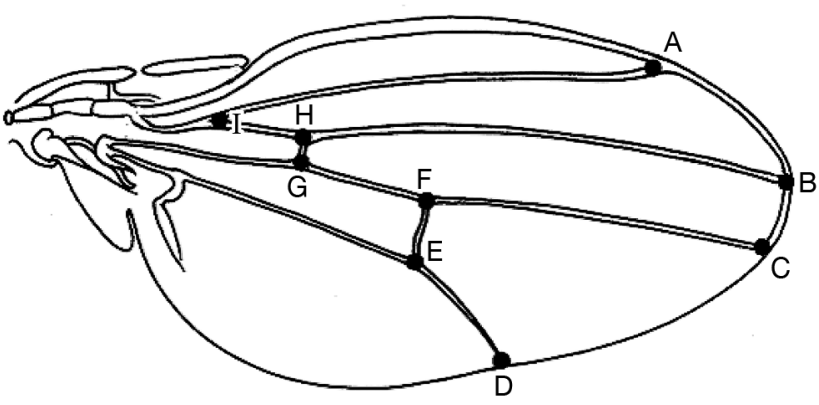

Fig. 1. The 9 landmarks used for analysis: the end of the 2nd to the 5th longitudinal vein $(A, B, C, D)$; the crosses between the posterior cross vein and the 4 th and 5 th longitudinal vein $(\mathrm{E}, \mathrm{F})_{i}$ the crosses between the anterior cross vein and the 2 nd and 3rd longitudinal veins $(\mathrm{G}, \mathrm{H})$; and the fusion of the 2nd and 3rd longitudinal vein (I). Picture replicated from Faurby et al. (2005)

ANOVA was performed on each strain and on each PC to analyse the effects of maternal age and temperature and their interactions.

Permutation $t$-tests were performed to analyse the effect of maternal age on each strain at each temperature in each PC.

The differences in the degree of phenotypic plasticity between the parental strains and the $F_{1}$ strains of wing length measured as the distance between landmarks $\mathrm{A}$ and $\mathrm{D}$, wing width as the distance between landmarks $\mathrm{B}$ and $\mathrm{H}$, and $\log$ (wing length/wing width) were tested by comparing the absolute values of the slopes of the regressions between 20 and $25^{\circ} \mathrm{C}$ and 25 and $28^{\circ} \mathrm{C}$, respectively, by means of a Z-test (Zar 1999). Significant differences between the absolute values of the slopes between offspring of young and old mothers imply that transgenerational plasticity or maternal effect of age is significant in the traits investigated.

All statistic analyses were performed using the software PAST (Hammer et al. 2001) and JMP (Statview 2006).

\section{RESULTS}

All measurements loaded highly positively on PC1 which can therefore be seen as a measure of overall size (Bookstein 1998). All remaining PCs, thus, express independent shape variation which cannot be explained by allometric size variation. In Strain 1, PC1 explained $76.9 \%$ of the variation, while PC2 accounted for $9.0 \%$. In Strain 2, PC1 and PC2 accounted for 81.5 and $6.3 \%$ of the variation, respectively. The results of the 2-way ANOVAs can be seen in Table 1. For PC1, both strains had a highly significant effect of temperature, while the effect of age was strain-specific. Strain 1 had a 
Table 1. Two-way ANOVAs analysing the effects of temperature and maternal age in 2 Drosophila mercatorum strains. ANOVAs were performed separately for each strain. ${ }^{\Delta}: \mathrm{p}<$ $0.1 ;{ }^{* * *}: \mathrm{p}<0.001 ;$ ns: non-significant. $\mathrm{p}$-values are Bonferroni corrected $(\mathrm{K}=2)$

\begin{tabular}{|c|c|c|c|c|c|c|}
\hline $\mathrm{PC}$ & Strain & Factor & SS & df & $F$ & $\mathrm{p}$ \\
\hline \multirow[t]{8}{*}{1} & \multirow[t]{4}{*}{1} & Age & 2.38 & 1 & 61.5 & $* * *$ \\
\hline & & Temperature & 129.3 & 2 & 1667 & $* * *$ \\
\hline & & Interaction & 0.27 & 2 & 3.5 & $\Delta$ \\
\hline & & Within & 28.28 & 729 & & \\
\hline & \multirow[t]{4}{*}{2} & Age & 0.06 & 1 & 1.1 & ns \\
\hline & & Temperature & 156.9 & 2 & 1531 & $* * *$ \\
\hline & & Interaction & 2.26 & 2 & 22.1 & $* * *$ \\
\hline & & Within & 41.01 & 801 & & \\
\hline \multirow[t]{8}{*}{2} & \multirow[t]{4}{*}{1} & Age & 4.25 & 1 & 787.8 & $* * *$ \\
\hline & & Temperature & 0.49 & 2 & 45 & $* * *$ \\
\hline & & Interaction & 0.31 & 2 & 28.3 & $* * *$ \\
\hline & & Within & 3.39 & 729 & & \\
\hline & \multirow[t]{4}{*}{2} & Age & 1.45 & 1 & 274.5 & $* * *$ \\
\hline & & Temperature & 0.36 & 2 & 34 & $* * *$ \\
\hline & & Interaction & 0.15 & 2 & 13.8 & $* * *$ \\
\hline & & Within & 4.23 & 801 & & \\
\hline
\end{tabular}

highly significant effect of age and a marginally significant age $\times$ temperature interaction, while Strain 2 had a non-significant effect of age but a highly significant age $\times$ temperature interaction. The results for $\mathrm{PC} 2$ were consistent between strains with respect to age, temperature and their interaction (all significant).

The results of the permutation $t$-tests can be seen in Table 2. There was generally a significant effect of parental age in all comparisons. This effect was always highly significant in PC2 and was highly significant for Strain 1 in PC1. For Strain 2 in PC2, parental age was highly significant at $28^{\circ} \mathrm{C}$, whereas it was only signifi-

Table 2. Permutation $t$-tests comparing the effect of maternal age (young: 3 to $6 \mathrm{~d}$; old: 15 to $18 \mathrm{~d}$ ) for PC1 and PC2 at each temperature $\left(20,25\right.$ and $\left.28^{\circ} \mathrm{C}\right)$ in each strain of Drosophila mercatorum. ${ }^{\Delta}: \mathrm{p}<0.1_{i}{ }^{*}: \mathrm{p}<0.05 i^{* *}: \mathrm{p}<0.01_{i^{* * *}}: \mathrm{p}<0.001$. $\mathrm{p}$-values are Bonferroni corrected $(\mathrm{K}=6)$

\begin{tabular}{|c|c|c|c|c|c|}
\hline $\mathrm{PC}$ & $\begin{array}{c}\text { Temperature } \\
\left({ }^{\circ} \mathrm{C}\right)\end{array}$ & Strain & $\begin{array}{l}\text { Mean } \\
\text { young }\end{array}$ & $\begin{array}{l}\text { Mean } \\
\text { old }\end{array}$ & $\mathrm{p}$ \\
\hline \multirow[t]{6}{*}{1} & 20 & 1 & 0.56 & 0.65 & $* *$ \\
\hline & & 2 & 0.54 & 0.61 & $\Delta$ \\
\hline & 25 & 1 & -0.02 & 0.12 & ${ }^{* * *}$ \\
\hline & & 2 & 0.04 & 0.11 & * \\
\hline & 28 & 1 & -0.57 & -0.41 & $* * *$ \\
\hline & & 2 & -0.60 & -0.48 & ${ }^{* * *}$ \\
\hline \multirow[t]{6}{*}{2} & 20 & 1 & -0.07 & 0.02 & $* * *$ \\
\hline & & 2 & -0.04 & 0.02 & ${ }^{* * *}$ \\
\hline & 25 & 1 & -0.05 & 0.10 & $* * *$ \\
\hline & & 2 & -0.01 & 0.06 & $* * *$ \\
\hline & 28 & 1 & -0.08 & 0.11 & $* * *$ \\
\hline & & 2 & -0.07 & 0.05 & $* * *$ \\
\hline
\end{tabular}

cant at $25^{\circ} \mathrm{C}(\mathrm{p}=0.028)$ and marginally significant at $20^{\circ} \mathrm{C}(\mathrm{p}=0.097)$.

The plastic responses in wing length to temperature were non-linear. The plastic response of wing length did not differ between age classes in either strain, as there were no differences in the slopes. Changes in wing width with temperature between age classes were different in one case. In Strain 1, width showed a larger decrease in the offspring of young mothers from 20 to $25^{\circ} \mathrm{C}$ than offspring of old mothers $(\mathrm{p}<0.05)$. This difference in wing width gave rise to a significant difference in wing aspect in Strain 1 from 20 to $25^{\circ} \mathrm{C}$. In Strain 2, although neither wing length nor wing width had significantly different responses to temperature, their composite trait, wing aspect, significantly increased from 25 to $28^{\circ} \mathrm{C}$.

\section{DISCUSSION}

The results of the 2-way ANOVA showed that wing size and shape were highly significantly affected by temperature and maternal age in most cases. In addition, the response was strain-specific, i.e. dependent on the maternal genotype.

As expected in the non-extreme temperature range, wing size decreased with temperature in both strains as predicted by the temperature-size rule for ectotherms (Atkinson \& Sibly 1997, Angilletta et al. 2004). Less attention has been given to the parental effects of age on progeny size. We found that progeny of old mothers had larger wings than that of young mothers (Fig. 2, Table 2). This is in line with the results of previous studies on wing size (McIntyre \& Gooding 2000, Andersen et al. 2005, Faurby et al. 2005, Røgilds et al. 2005) and body size of ectotherms (McIntyre \& Gooding 2000, Sakwinska 2004).

Parental effects are difficult to disentangle from genetic and environmental variation and therefore clonal or highly inbred organisms are often used in such experiments. Importantly, the experimental design we used enabled us to investigate parental effects of highly heterozygous, yet genetically virtually identical, individuals. The results show that the wing size effects of maternal age found in previous studies (Faurby et al. 2005, Kjærsgaard et al. 2007) are not an artifact or consequence of inbreeding or parthenogenetic reproduction per se, but appear to be a general trend for Drosophila. Inbreeding is known to affect longevity (Vermeulen \& Bijlsma 2004), so it could be expected that inbreeding may change the phenotypic correlations, but this is apparently not the case for wing size. Even so, the effect of inbreeding should not be ignored as it may reduce wing size, wing width and egg to adult viability (Joubert \& Bijlsma 2010, this Spe- 

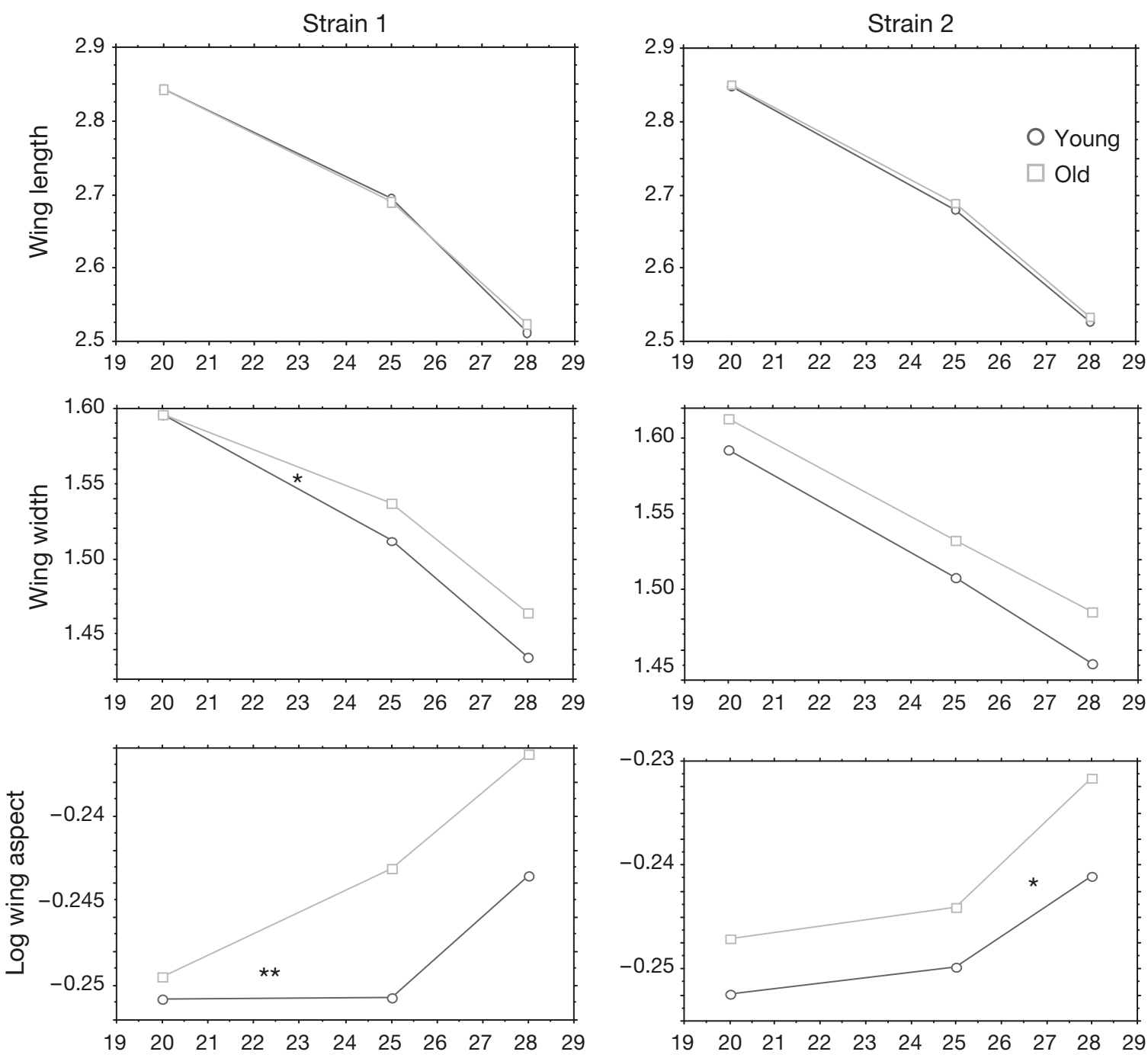

Fig. 2. Drosophila mercatorum. Reaction norms for the traits wing length, wing width and wing aspect comparing offspring of young ( 3 to $6 \mathrm{~d}$ ) and old (15 to $18 \mathrm{~d}$ ) mothers for each strain. Distance measures are in pixels. Significant differences in slope connecting adjacent temperatures are shown on graphs. ${ }^{*}: \mathrm{p}<0.05_{i}{ }^{* *}: \mathrm{p}<0.01$

cial). Reduced viability will lower recruitment and further increase the average age of the population. Therefore, increased levels of inbreeding, a likely consequence of global warming (Pertoldi \& Bach 2007), can influence wing characters both directly and indirectly via the interactions with maternal age.

Since wing size is highly correlated with body size (Wilkinson et al. 1990), and as large body size often confers high fitness (Kazmer \& Luck 1995, Reeve et al. 2000, Bochdanovits \& de Jong 2003), it seems that old mothers produce more fit offspring than young mothers. However, previous studies of Drosphila mercatorum have shown that progeny of old mothers also exhibit higher developmental instability, at least in benign environments (Faurby et al. 2005, Røgilds et al. 2005). The advantages of larger body size may thus, at least partially, be outweighed by high developmental instability.
As for wing shape variation, the 2-way ANOVA revealed highly significant differences for temperature, age and their interaction in all cases for PC2, which captured the most important shape variation (Table 1). The same was the case for the permutation $t$-tests for differences between progeny of young and old mothers within temperature treatments (Table 2). Contrasting this information with the results of the $Z$-tests for differences in plasticity among progeny of young and old mothers shows that most variation in wing shape was associated with changes in the width of the wings, as there were no significant differences in wing length in either strain. In Strain 1 there was also no significant difference in wing width, but the difference present was still sufficient to make the wing aspect measure significantly different between the 2 progeny groups from 25 to $28^{\circ} \mathrm{C}$. As mentioned earlier, 
there is some evidence that points to an adaptive role of wing shape. The most direct evidence is provided by Kölliker-Ott et al. (2003), who studied wing shape of parasitoid Trichogramma wasps in a field release experiment. They found that wasps that reached the oviposition sites differed significantly in shape from those that did not. Furthermore, fitness also increased with wing size. In a comparative study, Carreira et al. (2006) investigated the associations between wing morphology and dispersal in the sibling species Drosophila buzzatii and D. koepferae. They found that $D$. koepferae had narrower wings and larger body size than $D$. buzzatii, which could be an adaptation to longer dispersal distances between its cactus hosts. The narrowing was associated with a relative lengthening of the distal part of the wing, which has also been found in other studies (Hoffmann \& Shirriffs 2002, Santos et al. 2006). Furthermore, an estimate of wing loading supported the theory that dispersal capacity is inversely related to wing loading.

Following this line of evidence, it would seem that progeny of young mothers in the present study had a better dispersal capacity due to a lower wing aspect, but the fact that we did not measure thorax length complicates matters. While wing length is highly correlated with body size, so is wing width (Wilkinson et al. 1990). We therefore cannot say whether the difference actually confers better dispersal capacity or whether the progeny of old mothers are bigger and thereby could have a lower wing loading due to a relatively larger thorax.

Plasticity responses are not always adaptive (Dewitt et al. 1998, Kristensen et al. 2008, van Buskirk \& Steiner 2009). Whether a plastic response to different developmental temperatures is adaptive can be estimated by comparing populations adapted to different temperature regimes by transplant or common garden experiments. If plastic responses of a given genotype to a given temperature regime match the phenotypic values of the locally adapted populations, it is most likely adaptive (e.g. Trussell 2000). In the present study we had no strains selected for the 3 temperatures, but the results qualitatively match those of Hoffmann \& Shirriffs (2002; their Fig. 2, outer wing aspect), who saw a relatively steep increase in wing aspect of Drosophila serrata at high temperatures comparing populations along a latitudinal cline. These responses were purely genetic as flies were all reared at a constant $25^{\circ} \mathrm{C}$ temperature in the laboratory. A similar pattern was found by Loh et al. (2008) in Zaprionus indianus, suggesting that a relative broadening of the wing is a characteristic response to increased temperature or smaller body size (Starmer \& Wolf 1989).

Whenever plastic responses to some environmental factor occur towards an adaptive peak in the fitness landscape, they may help a population to survive stressful situations. This can be mediated by the process first noted by Baldwin (1896) and since known as the Baldwin effect, which states that plasticity can be crucial for the ability of a population to embrace environmental change. In fact, plasticity may increase under some circumstances. This initial buffering capacity may lead to genetic assimilation (Waddington 1942, Pigliucci et al. 2006) and canalisation in the adaptive direction in the novel environment.

Furthermore, differences in various performance measures between relatively constant and fluctuating temperature regimes have been mostly attributed to a non-linear relationship between trait values and temperature (Ruel \& Ayres 1999, Ragland \& Kingsolver 2008). If the trait function to temperature is accelerating, the mean trait value will be larger in a fluctuating regime than in a constant regime, whereas it will be smaller if the function is decelerating (Ruel \& Ayres 1999). Hence we expect that, in a regime of fluctuating temperature with the same mean as the constant temperatures used in this experiment, the proportion between the trait values of the offspring derived from young and old parents, respectively, will become larger (but see Kingsolver et al. 2009).

Ackowledgements. This study has been partly supported by a Marie Curie Transfer of Knowledge Fellowship BIORESC of European Community's Sixth Framework Program (contract no. MTKD-CT-2005-029957). Furthermore, we thank the ConGen Program and the ThermAdapt program (funded by the European Science Foundation) for this opportunity to discuss and publish our results in connection to the workshop 'Evolutionary and physiological adaptation to climateinduced environmental changes' held in Białowieża, Poland, July 2009. Finally, we thank the Danish Natural Science Research Council for financial support to C.P. (grant nos. 2101-0526 and 21-03-0125).

\section{LITERATURE CITED}

Abramoff MD, Magelhaes PJ, Ram SJ (2004) Image processing with ImageJ. Biophotonics International 11:36-42

Andersen DH, Pertoldi C, Scali V, Loeschcke V (2005) Heat stress and age induced maternal effects on wing size and shape in parthenogenetic Drosophila mercatorum. J Evol Biol 18:884-892

Angilletta MJ Jr, Niewiarowski PH, Dunham AE, Leache AD, Porter WP (2004) Bergmann's clines in ectotherms: illustrating a life-history perspective with sceloporine lizards. Am Nat 164:E168-E183

Atkinson D, Sibly RM (1997) Why are organisms usually bigger in colder environments? Making sense of a life history puzzle. Trends Ecol Evol 12:235-239

Azevedo RBR, James AC, McCabe J, Partridge L (1998) Latitudinal variation of wing: thorax size ratio and wing-aspect ratio in Drosophila melanogaster. Evolution 52:1353-1362

Badyaev AV, Uller T (2009) Parental effects in ecology and evolution: mechanisms, processes and implications. Philos Trans R Soc Lond B 364:1169-1177 
Baldwin JM (1896) A new factor in evolution. Am Nat 30: 441-451

Bitner-Mathé BC, Klaczko LB (1999) Plasticity of Drosophila melanogaster wing morphology: effects of sex, temperature and density. Genetica 105:203-210

Bochdanovits Z, de Jong G (2003) Temperature dependent larval resource allocation shaping adult body size in Drosophila melanogaster. J Evol Biol 16:1159-1167

Bookstein FL (1989) Size and shape: a comment on semantics. Syst Zool 38:173-180

Breuker CJ, Patterson JS, Klingenberg CP (2006) A single basis for developmental buffering of Drosophila wingshape. PLoS ONE 1:e7

- Carreira VP, Soto IM, Hasson E, Fanara JJ (2006) Patterns of variation in wing morphology in the cactophilic Drosophila buzzatii and its sibling $D$. koepferae. J Evol Biol 19:1275-1282

> Cavicchi S, Giorgi G, Natali V, Guerra D (1991) Temperaturerelated divergence in experimental populations of Drosophila melanogaster. IV. Fourier and centroid analysis of wing shape and relationship between shape variation and fitness. J Evol Biol 4:141-159

> Chown SL, Hoffmann AA, Kristensen TN, Angilletta MJ Jr, Stenseth NC, Pertoldi C (2010) Adapting to climate change: a perspective from evolutionary physiology. Clim Res 43: $3-15$

> David JR, Moreteau B, Gauthier JP, Pétavy G, Stockel A, Imasheva MA (1994) Reaction norms of size characters in relation to growth temperature in Drosophila melanogaster: an isofemale line analysis. Genet Sel Evol 26: $229-251$

> David JR, Gibert P, Gravot E, Petavy G, Morin JP, Karan D, Moreteau B (1997) Phenotypic plasticity and developmental temperature in Drosophila: analysis and significance of reaction norms of morphometrical traits. J Therm Biol 22:441-451

> Dewitt TJ, Sih A, Wilson DS (1998) Costs and limits of phenotypic plasticity. Trends Ecol Evol 13:77-81

> Faurby S, Kjaersgaard A, Pertoldi C, Loeschcke V (2005) The effect of maternal and grandmaternal age in benign and high temperature environments. Exp Gerontol 40: 988-996

Gilchrist GW, Huey RB (2004) Plastic and genetic variation in wing loading as a function of temperature within and among parallel clines in Drosophila subobscura. Integr Comp Biol 44:461-470

Gilchrist AS, Azevedo RBR, Partridge L, O'Higgins P (2000) Adaptation and constraint in the evolution of Drosophila melanogaster wing shape. Evol Dev 2:114-124

Halliwell B, Gutteridge JMC (1999) Free radicals in biology and medicine, 3rd edn. Oxford University Press, New York

Hammer Ø, Harper DAT, Ryan PD (2001) PAST: paleontological statistics software package for education and data analysis. Palaeontol Electronica 4:1-9

> Hercus MJ, Hoffmann AA (2000) Maternal and grandmaternal age influence offspring fitness in Drosophila. Proc R Soc Lond B 267:2105-2110

Hoffmann AA, Shirriffs J (2002) Geographic variation for wing shape in Drosophila serrata. Evolution 56:1068-1073

Hoffmann AA, Ratna E, Sgrò CM, Barton M, Blacket M, Hallas R, De Garis S, Weeks AR (2007) Antagonistic selection between adult thorax and wing size in field released Drosophila melanogaster independent of thermal conditions. J Evol Biol 20:2219-2227

Imasheva AG, Loeschcke V, Zhivotovsky LA, Lazebny OE (1998) Stress temperatures and quantitative variation in Drosophila melanogaster. Heredity 81:246-253
Joubert D, Bijlsma R (2010) Interplay between habitat fragmentation and climate change: inbreeding affects the response to thermal stress in Drosophila melanogaster. Clim Res 43:57-70

Kazmer DJ, Luck RF (1995) Field tests of the size fitness hypothesis in the egg parasitoid Trichogramma pretiosum. Ecology 76:412-425

Kingsolver JG, Ragland GJ, Diamond SE (2009) Evolution in a constant environment: thermal fluctuations and thermal sensitivity of laboratory and field populations of Manduca sexta. Evolution 63:537-541

Kjærsgaard A, Faurby S, Andersen DH, Pertoldi C, David JR, Loeschcke V (2007) Effects of temperature and maternal and grandmaternal age on wing shape in parthenogenetic Drosophila mercatorum. J Therm Biol 32:59-65

Kölliker-Ott UM, Blows MW, Hoffmann AA (2003) Are wing size, wing shape and asymmetry related to field fitness of Trichogramma egg parasitoids? Oikos 100:563-573

Krag K, Thomsen H, Faurby S, Kjaersgaard A, Tejedo M, Loeschcke V, Pertoldi C (2009) Consequences of outbreeding on phenotypic plasticity in Drosophila mercatorum wings. Evol Ecol 23:403-415

Kristensen TN, Hoffmann AA, Overgaard J, Sørensen JG, Hallas R, Loeschcke V (2008) Costs and benefits of cold acclimation in field-released Drosophila. Proc Natl Acad Sci USA 105:216-221

Lerner IM (1954) Genetic homeostasis. Oliver and Boyd, London

- Loeschcke V, Bundgaard J, Barker JSF (1999) Reaction norms across and genetic parameters at different temperatures for thorax and wing size traits in Drosophila aldrichi and D. buzzatii. J Evol Biol 12:605-623

Loeschcke V, Bundgaard J, Barker JSF (2000) Variation in body size and life history traits in Drosophila aldrichi and D. buzzatii from a latitudinal cline in eastern Australia. Heredity 85:423-433

Loh R, David JR, Debat V, Bitner-Mathé BC (2008) Adaptation to different climates results in divergent phenotypic plasticity of wing size and shape in an invasive drosophilid. J Genet 87:209-217

> McIntyre GS, Gooding RH (2000) Effects of maternal age on larval competitiveness in house flies. Heredity 85:480-489

Mousseau TA, Fox CW (1998) The adaptive significance of maternal effects. Trends Ecol Evol 13:403-407

Nieminen M, Siljander M, Hanski I (2004) Structure and dynamics of Melitaea cinxia metapopulations. In: Ehrlich PR, Hanski I (eds) On the wings of checkerspots: a model system for population biology. Oxford University Press, Oxford, p 63-91

Pertoldi C, Bach LA (2007) Evolutionary aspects of climateinduced changes and the need for multidisciplinarity. J Therm Biol 32:118-124

Pertoldi C, Sorensen JG, David JR, Loeschcke V (2006) Lerner's theory on the genetic relationship between heterozygosity, genomic co-adaptation, and developmental instability revisited. Evol Ecol Res 8:1487-1498

> Petavy G, Morin JP, Moreteau B, David JR (1997) Growth temperature and phenotypic plasticity in two Drosophila sibling species: probable adaptive changes in flight capacities. J Evol Biol 10:875-887

Pigliucci M, Murren CJ, Schlichting CD (2006) Phenotypic plasticity and evolution by genetic assimilation. J Exp Biol 209:2362-2367

> Pulliam HR, Danielson BJ (1991) Sources, sinks, and habitat selection: a landscape perspective on population dynamics. Am Nat 137:S50-S66

Ragland GJ, Kingsolver JG (2008) The effect of fluctuating 
temperatures on ectotherm life-history traits: comparisons among geographic populations of Wyeomyia smithii. Evol Ecol Res 10:29-44

Reed SC, Williams CM, Chadwick LE (1942) Frequency of wing-beat as a character for separating species races and geographic varieties of Drosophila. Genetics 27:349-361

Reeve MW, Fowler K, Partridge L (2000) Increased body size confers greater fitness at lower experimental temperature in male Drosophila melanogaster. J Evol Biol 13:836-844

Røgilds A, Andersen DH, Pertoldi C, Dimitrov K, Loeschcke V (2005) Maternal and grandmaternal age effects on developmental instability and wing size in parthenogenetic Drosophila mercatorum. Biogerontology 6:61-69

Rossiter MC (1996) Incidence and consequences of inherited environmental effects. Annu Rev Ecol Syst 27:451-476

Ruel JJ, Ayres MP (1999) Jensen's inequality predicts effects of environmental variation. Trends Ecol Evol 14:361-366

Sakwinska O (2004) Persistent maternal identity effects on life history traits in Daphnia. Oecologia 138:379-386

Santos M, Brites D, Laayouni H (2006) Thermal evolution of pre-adult life history traits, geometric size and shape, and developmental stability in Drosophila subobscura. J Evol Biol 19:2006-2021

Stalker HD (1980) Chromosome studies in wild populations of Drosophila melanogaster. II. Relationship of inversion frequencies to latitude, season, wing-loading and flight activity. Genetics 95:211-223

Starmer WT, Wolf LL (1989) Causes of variation in wing loading among Drosophila species. Biol J Linn Soc 37:247-261

Statview (2006) JMP statistical discovery software v. 4.0. Available at www.statview.com

Submitted: April 6, 2010; Accepted: May 27, 2010
Templeton AR, Johnston JS (1982) Life history evolution under pleiotropy and $\mathrm{K}$-selection in a natural population of Drosophila mercatorum. In: Barker JSF, Starmer WT (eds) Ecological genetics and evolution: the cactus-yeastDrosophila model system. Academic Press, Sydney, p 225-240

- Trussell GC (2000) Phenotypic clines, plasticity, and morphological trade-offs in an intertidal snail. Evolution 54: 151-166

van Buskirk J, Steiner UK (2009) The fitness costs of developmental canalization and plasticity. J Evol Biol 22:852-860

- Vermeulen CJ, Bijlsma R (2004) Changes in mortality patterns and temperature dependence of lifespan in Drosophila melanogaster caused by inbreeding. Heredity 92: 275-281

> Waddington $\mathrm{CH}$ (1942) Canalization of development and genetic assimilation of acquired characters. Nature 150: 563-565

Weber KE (1992) How small are the smallest selectable domains of form. Genetics 130:345-353

Wilkinson GS, Fowler K, Partridge L (1990) Resistance of genetic correlation structure to directional selection in Drosophila melanogaster. Evolution 44:1990-2003

Workman MS, Leamy LJ, Routman EJ, Cheverud JM (2002) Analysis of QTL effects on the size and shape of mandibular molars in mice. Genetics 160:1573-1586

Young AG, Clarke GM (2000) Genetics, demography and viability of fragmented populations. Cambridge University Press, Cambridge

Zar JH (1999) Biostatistical analysis. Prentice Hall, Upper Saddle River, NJ

Proofs received from author(s): July 11, 2010 